\title{
Predictive factors of lamivudine treatment success in a hepatitis B virus-infected pediatric cohort: A 10-year study
}

\author{
Yasmine Yousef ${ }^{1 *}$, Kathie Béland $\mathrm{MSc}^{1 *}$, Emmanuel Mas $\mathrm{MD}^{2}$, Pascal Lapierre $\mathrm{PhD}^{1}$, \\ Dorothée Bouron Dal Soglio $\mathrm{MD}^{3}$, Fernando Alvarez $\mathrm{MD}^{1,4}$
}

\begin{abstract}
Y Yousef, K Béland, E Mas, P Lapierre, D Bouron Dal Soglio, F Alvarez. Predictive factors of lamivudine treatment success in a hepatitis B virus-infected pediatric cohort: A 10-year study. Can J Gastroenterol 2012;26(7):429-435.
\end{abstract}

BACKGROUND: Hepatitis B virus (HBV) infections are responsible for the development of chronic hepatitis in 400 million people worldwide. Currently, no consensus exists as to when treatment should be initiated for pediatric patients.

OBJECTIVES: To evaluate the risks and predictive factors of success of lamivudine treatment in children with chronic, active HBV infection. METHODS: Forty-three children ( 22 male, median age 9.6 years) chronically infected with HBV and treated between 1998 and 2008 at CHU Ste-Justine (Montreal, Quebec) were included in the present chart review study. Inclusion criteria were detectable hepatitis B surface antigen and hepatitis $\mathrm{B}$ e antigen ( $\mathrm{HBeAg}$ ), minimum serum alanine aminotransferase (ALT) level of two times the upper limit of normal and detectable serum HBV DNA for at least three months. Patients received lamivudine for a minimum of six months (median 14 months). Genotyping was performed.

RESULTS: Lamivudine treatment was effective in $35 \%$ of cases ( 15 of 43) and overall virological response (during or after treatment) was achieved in $51 \%$ of patients. Three patients harboured suspected lamivudine-resistant mutations and five progressed to $\mathrm{HBeAg}$-chronic HBV. Predictive factors for success of treatment were: younger age at beginning of treatment $(\mathrm{P}=0.05)$, elevated ALT levels throughout treatment duration $(\mathrm{P}=0.003)$ and loss of $\mathrm{HBeAg}$ during treatment $(\mathrm{P}=0.016)$. Asian origin did not affect treatment success or spontaneous viral control during follow-up. HBV genotype did not influence treatment success.

CONCLUSIONS: Lamivudine treatment in a carefully selected cohort of HBV patients demonstrated a good rate of success and low incidence of mutation. Younger age at the beginning of treatment and high ALT levels during treatment predicted a positive outcome.

Key Words: Hepatitis B; Lamivudine; Pediatric; Predictive success factors
Cepatitis B virus (HBV) infections are responsible for the develop1 ment of chronic hepatitis in 400 million people worldwide and 600,000 in Canada $(1,2)$. In most cases, patients acquired the infection during childhood (1). It has been estimated that approximately $25 \%$ of chronically infected individuals, who contracted HBV in childhood, develop complications in adulthood such as cirrhosis and hepatocellular carcinoma and die of liver-related complications $(3,4)$. In addition to the risk of health complications, chronic HBV infections in childhood carry the risk of sexual transmission as children grow older and become sexually active.

\author{
Les facteurs prédictifs de réussite du traitement à la \\ lamivudine chez une cohorte de patients \\ pédiatriques infectés par le virus de l'hépatite $B$ : \\ une étude sur dix ans
}

\begin{abstract}
HISTORIQUE : Les infections par le virus de l'hépatite B (VHB) sont responsables de l'apparition d'hépatite chronique chez 400 millions de personnes de par le monde. Il n'existe pas de consensus quant au moment d'amorcer le traitement chez les patients pédiatriques.

OBJECTIFS : Évaluer les risques et les facteurs prédictifs de réussite du traitement à la lamivudine chez les enfants atteints d'une infection active par le VHB chronique

MÉTHODOLOGIE : Quarante-trois enfants (22 garçons, âge médian de 9,6 ans) atteints d'une infection chronique par le VHB et traités au CHU Sainte-Justine (Montréal, Québec) entre 1998 et 2008 ont participé à la présente étude de dossiers. Les critères d'inclusion étaient un antigène de surface de l'hépatite $B$ et un antigène e de l'hépatite $B(\mathrm{HBe} A G)$ décelables, un taux d'alanine-aminotransférase sérique (ALT) deux fois plus élevé que la normale supérieure et un ADN du VHB décelable dans le sérum pendant au moins trois mois (médiane de 14 mois). Les chercheurs ont procédé à un génotypage.
\end{abstract}

RÉSULTATS : Le traitement à la lamivudine était efficace dans $35 \%$ des cas (15 cas sur 43) et on observait une réponse virologique globale (pendant ou après le traitement) chez $51 \%$ des patients. Trois patients présentaient des mutations qu'on présumait découler d'une résistance à la lamivudine et cinq ont évolué vers une VHB chronique HBeAg-positive. Les facteurs prédictifs de réussite du traitement étaient un plus jeune âge en début de traitement $(\mathrm{P}=0,05)$, un taux d'ALT élevé pendant toute la durée du traitement $(\mathrm{P}=0,003)$ et une perte de l'HBeAg pendant le traitement $(P=0,016)$. L'origine asiatique n'avait pas d'influence sur la réussite $d u$ traitement ou sur le contrôle viral spontané pendant le suivi. Le génotype du VHB n'avait pas d'incidence sur la réussite du traitement.

CONCLUSIONS : Le traitement à la lamivudine dans une cohorte de patients atteints du VHB soigneusement sélectionnée s'associe à un fort taux de réussite et à une faible incidence de mutation. Un âge plus jeune en début de traitement et des taux d'ALT élevés pendant le traitement étaient indicateurs d'une issue positive.

These risks of viral transmission and long-term health complications call for prevention through education and close clinical monitoring, but also for viral control with optimized therapeutic strategies. Currently, drugs licensed for the treatment of HBV chronic infection in pediatric populations are interferon-alpha (INF-alpha) and lamivudine (LAM), which have similar hepatitis $\mathrm{B}$ e antigen ( $\mathrm{HBeAg}$ ) seroconversion rates (5-7). INF therapy has the advantage of finite duration of treatment, lack of acquired drug resistance and higher likelihood of hepatitis B surface antigen ( $\mathrm{HBsAg}$ ) clearance over LAM. However, INF use is associated with many adverse effects

*Authors who contributed equally to this work.

${ }^{1}$ Division of Gastroenterology, Hepatology and Nutrition, CHU Sainte-Justine, Montreal, Quebec; ${ }^{2}$ Division of Gastroenterology, Hepatology,

Nutrition and Diabetology, Children's Hospital, Toulouse, France; ${ }^{3}$ Division of Pathology, CHU Sainte-Justine; ${ }^{4}$ Department of Paediatrics, University of Montreal, Montreal, Quebec

Correspondence: Dr Fernando Alvarez, Division of Gastroenterology, Hepatology and Nutrition, CHU Sainte-Justine, 3175 Côte Ste-Catherine,

Montreal, Quebec H3T 1C5. Telephone 514-345-4626, fax 514-345-4999, e-mail fernando.alvarez@umontreal.ca

Received for publication June 27, 2011. Accepted October 12, 2011 
including derangement of weight gain and growth, discomfort on administration and flu-like syndrome (5). LAM is known to induce drug-resistant mutations (7-9) and the ideal duration of the treatment remains unclear; however, it is administered orally, better-tolerated and safer $(5,8)$.

To date, no consensus exists as to if and when treatment should be initiated in pediatric patients. HBeAg seroconversion is more sustainable and HBV recurrence occurs less frequently in childhood than in adult patients $(5,10,11)$. Children with chronic HBV infections are often in an immune tolerance phase and do not benefit from treatment (12). Actual knowledge suggests that only children with immune active disease should undergo treatment $(5,7,13,14)$.

An important part of our knowledge concerning the pediatric response to LAM treatment has come from one, extensively studied, single placebo-controlled cohort $(7,14-16)$. Studies on different cohorts have validated and expanded these findings as well as their applicability to different populations $(5,13,17)$. The aim of our study was to evaluate the risks and predictive factors of LAM treatment success in a Canadian pediatric population with chronic HBV infection who were in an immune-active phase.

\section{Population}

\section{METHODS}

The present retrospective study reviewed the charts of all children with chronic HBV infection and treated with LAM at St Justine Children's Hospital in Montreal, Quebec, between July 1998 and July 2008, who fulfilled the inclusion criteria. During this period, 43 children $(22$ male) received LAM treatment and fulfilled the following inclusion criteria: detectable $\mathrm{HBs} \mathrm{Ag}$ and $\mathrm{HBeAg}$ (for at least three months), minimum serum alanine aminotransferase (ALT) level of two times the upper limit of normal (ULN; normal $25 \mathrm{IU} / \mathrm{mL}$ ) and detectable serum HBV DNA for at least three months. All other causes of elevated ALT levels were discarded at inclusion. The median age at beginning of treatment was 9.6 years (range 1.1 to 18.4 years). HBV infection occurred in more cases vertically (or perinatally) $(86 \%)$ than were horizontally transmitted $(14 \%)$. No patients were coinfected with either hepatitis C virus or HIV; one patient was infected with hepatitis D virus. Two patients received IFN-alpha before the study. The present study was approved by the institutional ethical committee of CHU Sainte-Justine and was conducted in conformity with the guidelines for human experimentation.

\section{Study design}

All patients received $3 \mathrm{mg} / \mathrm{kg} /$ day to a maximum of $100 \mathrm{mg}$ of LAM orally daily. The duration of treatment was determined on a case-bycase basis (median 14 months, range five to 38 months). Treatment was discontinued if: the physician determined that treatment was successful (see definitions), a LAM-resistant mutation occurred or treatment was unsuccessful. Patients were assessed every 12 weeks after initiation of therapy for biochemical markers of liver disease and HBV serological markers: serum HBV DNA according to either a hybrid capture assay (Digene, Qiagen, USA [detection limit $1030 \mathrm{UI} / \mathrm{mL}$ ]) if assessed before 2005, or HBV test (COBAS AmpliPrep/COBAS TaqMan HBV Test (Roche, USA [detection limit $20 \mathrm{UI} / \mathrm{mL}$ ]) if assessed after 2005, and HBsAg and HBeAg by automated immunochemical assay (AxSYM, Abbot Laboratories, USA). Thirty-three patients were biopsied before the beginning of LAM treatment $(48 \mathrm{~h}$ to seven days before treatment) and assessed blindly at the end of the study by a single pathologist using the METAVIR algorithm (18). There were no reports of lack of adherence to therapy and no withdrawals. Patients were followed post-treatment for a mean $( \pm S D)$ of $48.5 \pm 32.2$ months, eight were lost to follow-up before the end of treatment. Treatment risk, such as development of virus mutations or adverse effects, were evaluated based on clinical data (see definitions).

\section{Definitions}

HBV virological response was defined as a loss of HBeAg and detectable serum HBV DNA $(7,15)$. Seroconversion-e implied a virological response along with normalization of ALT level and acquisition of hepatitis B e antibody (HBeAb) (5,7,15). A successful outcome was defined as sustained normalization of ALT levels and HBV virological response during the LAM treatment period and follow-up (17). LAMresistant mutations were suspected in patients whose HBV DNA concentrations declined then subsequently increased with no decline in $\mathrm{HBeAg}$ and no appearance of $\mathrm{HBeAb}$. Precore mutations were suspected in $\mathrm{HBe}$-seroconverted patients who maintained increased levels of HBV DNA (patients progressing to $\mathrm{HBeAg}$-negative chronic HBV).

\section{Genotyping}

Viral DNA was prepared from $200 \mu \mathrm{L}$ of frozen serum using the QIAamp MinElute Virus Spin kit (Qiagen, USA) according to manufacturer's instructions or by microwave technique (19). HBV DNA was amplified by polymerase chain reaction (PCR) using HBV primers for the $S$ gene (20). In cases where an amplicon was not visible on an agarose gel, a nested PCR was performed using forward primer position 302 to 319 , and reverse primer position 741 to 760 . Genotyping was performed on PCR products by restriction fragment length polymorphism using TasI and HinfI restriction enzymes (Fermentas, Canada) (20).

\section{Statistical analysis}

All statistical analyses were performed using SPSS version 17.0 (IBM Corporation, USA). All statistical tests ( $\chi^{2}$, Fisher's exact test, unpaired $t$ test and ANOVA) for comparison between success and failure of treatment groups and resulting $\mathrm{P}$ values were two tailed. Kaplan-Meyer survival curves were used to illustrate cumulative virological response in different groups, and groups were compared using the Mandel-Cox log-rank test. $\mathrm{P} \leq 0.05$ was considered to be statistically significant.

\section{RESULTS}

\section{Efficacy of treatment in the studied population}

Baseline demographic and clinical characteristics of chronically HBVinfected children treated with LAM are summarized in Supplemental Table 1. Approximately one-half of the children were of Asian descent (22 of 43). Median serum ALT level at the beginning of treatment (highest value within six months of the beginning) was $3.7 \times \mathrm{ULN}$ (mean $7 \times U L N \pm 8.4$; range $2 \times U L N$ to $43 \times U L N$ ). The highest value within the six months preceding treatment was used to assess whether the serum ALT levels were a predictive factor of response (13). The median serum HBV DNA level at baseline was $7.64 \log _{10}$. Based on liver biopsy data, patients had a median grade of liver inflammation of 1 and median stage of liver fibrosis score of 1 at baseline. One patient received prednisone and mycophenolate mofetil during the course of treatment.

Fifty-one per cent of patients (22 of 43) achieved a virological response over the course of the study period (mean follow-up $48.5 \pm 32.2$ months). Thirty-five per cent of all patients (15 of 43) achieved this response while under LAM therapy (period of treatment: median 14 months, range five to 38 months) and were thus considered to have a successful response to treatment (Table 1). The mean time to response to LAM therapy was 10.1 months (Figure 1). For the 15 patients who experienced a successful response to LAMtreatment: four achieved virological response within the first six months of treatment, six reached this response between six and 12 months of treatment and five more in the second year of treatment (Supplemental Figure 1). After 12 months of treatment, 23\% of all patients (10 of 43) had already achieved virological response (Supplemental Figure 1). When patients achieved a virological response after the first year of treatment, LAM was discontinued. LAM therapy was continued for a second year in 14 patients. Of these, five (33\%) experienced a successful response to treatment during this period. After stopping LAM treatment, $50 \%$ of patients who experienced a poor outcome to treatment achieved spontaneous viral control within 3.5 years (seven of 28). 
TABLE 1

\section{Overall effect of lamivudine treatment}

\begin{tabular}{lc}
\hline Treatment success & $28(65.1)$ \\
No & $15(34.9)$ \\
Yes & \\
Overall virological response & $21(48.8)$ \\
No & $22(51.2)$ \\
Yes & \\
Seroconversion-e & $17(39.5)$ \\
No & $24(55.8)$ \\
Yes & $2(4.7)$ \\
Transient & \\
Seroconversion-s & $37(86.0)$ \\
No & $6(14.0)$ \\
Yes & \\
Suspected lamivudine-resistance mutation & $40(93.0)$ \\
No & $3(7.0)$ \\
Yes & \\
Suspected precore mutation (HBeAg-chronic HBV) & $38(88.4)$ \\
No & $5(11.6)$ \\
Yes & \\
\hline
\end{tabular}

Data presented as n (\%). HBeAg Hepatitis B e antigen

Over a mean follow-up of more than four years, virological response obtained with LAM treatment was sustained in all patients except one. This patient experienced a virological recurrence with elevation of HBV DNA levels one year after treatment while maintaining seroconversion-e $\left(\mathrm{HBeAg}^{-}\right.$, anti- $\left.\mathrm{HBe}^{+}\right)$. This patient was suspected to have developed a precore mutation. The two patients who had received previous HBV treatments (IFN-alpha) both experienced a sustained virological response and seroconversion-e but this response occurred during LAM treatment in only one of the two. The number of non-naive patients who previously underwent LAM treatment was too small to draw any conclusions with respect to their response to LAM treatment.

Safety and LAM-associated resistance mutations

No safety problems or serious adverse effects associated with LAM therapy occurred in the present cohort of patients. LAM was well tolerated with no reported withdrawals. LAM-associated resistance mutations (such as YMDD mutations) were suspected in three patients (11\%). Furthermore, three of the children progressed to $\mathrm{HBeAg}$ negative chronic HBV (suspected precore mutation) and went on to achieve virological response (two under treatment and one spontaneously) (Table 2). HBV genotype was not associated with LAMresistant mutant occurrence (one of genotype $\mathrm{B}$, one of genotype $\mathrm{D}$ and one of unknown genotype $\left[\mathrm{P}=0.742, \chi^{2}\right.$ test $]$ ) or precore mutation (two patients infected with genotype $\mathrm{C}$, two with genotype $\mathrm{D}$ and one unknown $\left[\mathrm{P}=0.101, \chi^{2}\right.$ test $]$ ).

\section{Predictive factors of success at beginning of treatment}

Contrary to previous studies that reported a delayed virological response to LAM treatment in Asian populations (21,22), in the present study cohort, Asian descent (50\% of patients) was not associated with a reduced rate of success or with unusual virological response kinetics (spontaneous or due to treatment) (Figure 2).

Age at the beginning of treatment was the only factor significantly associated with treatment outcome (Table 2). In fact, younger age at the beginning of treatment led to a more favourable response to treatment $(\mathrm{P}=0.05$ [unpaired two-tailed $t$ test]). A Spearman negative correlation of $-0.307(\mathrm{P}=0.045)$ was found between age at the beginning of treatment and success of treatment.

Other potential predictive factors, such as ALT levels and liver inflammation, were not found to be significantly associated with treatment success $(\mathrm{P}=0.565$ and $\mathrm{P}=0.425$ [unpaired $t$ tests], respectively).

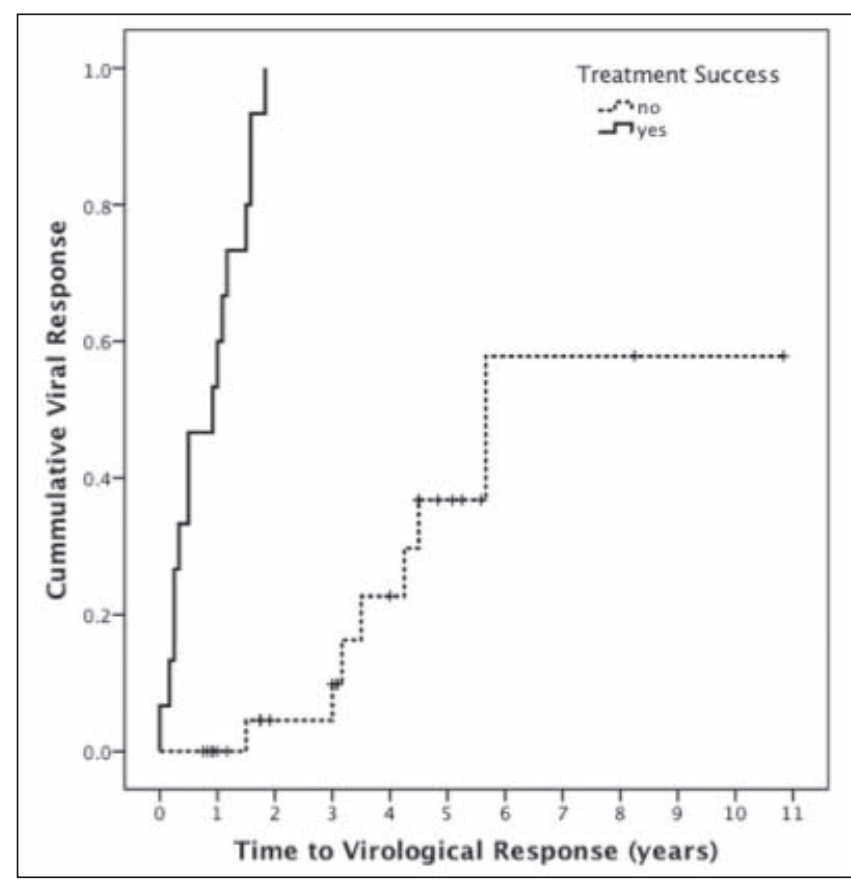

Figure 1) Hepatitis B virus (HBV)-infected children who experienced successful treatment with lamivudine achieved virological response in a short period of time. Cumulative proportion of children achieving virological response (loss of hepatitis $B$ e antigen and loss of detectable serum HBV DNA) with regard to success of treatment calculated by Kaplan-Meyer analysis. Censored data are depicted. ( $n=43, P<0.001$ [Mandel-Cox logrank test])

However, a tendency was observed for fibrosis score before treatment, with higher scores in patients who achieved a virological response during treatment $(\mathrm{P}=0.085$ [unpaired $t$ test]). HBV genotype was not associated with treatment outcome.

\section{Serological markers during treatment}

A statistically significant diminution of HBV DNA load was observed during treatment in patients with treatment success and failure $(\mathrm{P}=0.0245$ and $\mathrm{P}=0.0218$, respectively) (Figure $3 \mathrm{~A})$. At three months, patients with a positive outcome lost a mean of $2.88 \log _{10}$ of HBV DNA, whereas patients who did not achieve virological response with LAM lost a mean of $2.25 \log _{10}(\mathrm{P}=0.263$, unpaired two-tailed $t$ test $)$. At the end of treatment, HBV DNA was significantly lower in patients who successfully responded to treatment $(P=0.0001[n=31])$.

$\mathrm{HBeAg}$ loss during treatment was significantly higher in the treatment success group at three months $(n=31, P=0.016$ [Fisher's exact test]) and at the end of treatment $(n=26, P<0.0001$ [Fisher's exact test]). Nine patients experienced a loss of HBsAg (21\% of all patients), of whom eight achieved virological response during treatment, representing $53 \%$ of the treatment success group. Of the nine patients who seroconverted, two experienced transient losses. Of the seven patients who had a sustained loss, two lost HBsAg during treatment and five in follow-up years (Table 2).

Although there was no marked difference between ALT levels at baseline ( $n=36, P=0.565$ ), patients who successfully responded to treatment had consistently higher ALT levels throughout treatment (three months $\mathrm{P}=0.009$ [ $\mathrm{n}=35]$; six months $\mathrm{P}=0.003$ [ $\mathrm{n}=29$ ]; nine months $\mathrm{P}=0.049[\mathrm{n}=18]$ ) (Figure 3B). Patients with a positive outcome showed a tendency toward lower ALT values $(P=0.151[n=25])$.

\section{DISCUSSION}

Although there are few treatment options for chronic HBV infection in pediatric patients, LAM is one of the treatments appropriate for this patient population. Previous studies on pediatric response to LAM 
TABLE 2

Demographic, biochemical and viral characteristics of patients with treatment failure and successful response to treatment

\begin{tabular}{|c|c|c|c|c|}
\hline & \multicolumn{2}{|c|}{ Effective treatment } & \multirow[b]{2}{*}{ Total } & \multirow[b]{2}{*}{$\mathrm{P}$ (statistical test) } \\
\hline & No & Yes & & \\
\hline \multicolumn{5}{|l|}{ Sex } \\
\hline Male:female & $16: 12$ & $6: 9$ & $22: 21$ & 0.284 ( $\chi^{2}$ test); 0.347 (Fisher's exact test) \\
\hline Horizontal & 3 & 3 & $6(14)$ & 0.402 ( $\chi^{2}$ test); 0.647 (Fisher's exact test) \\
\hline Vertical (or perinatal) & 25 & 12 & $37(86)$ & \\
\hline Suspected YMDD mutation, n (\%) & $3(11)$ & $0(0)$ & $3(7)$ & 0.189 ( $\chi^{2}$ test); 0.541 (Fisher's exact test) \\
\hline Liver inflammation score, mean \pm SD & $1.1 \pm 0.6$ & $1.3 \pm 0.7$ & & $0.425(t$ test $)$ \\
\hline Liver fibrosis score, mean \pm SD & $1.3 \pm 0.9$ & $1.9 \pm 0.9$ & & 0.085 ( $t$ test) \\
\hline \multicolumn{5}{|l|}{ Descent, n (\%) } \\
\hline East Asian & $15(54)$ & $7(46)$ & $22(51)$ & 0.529 ( $\chi^{2}$ test $)$ \\
\hline African & $2(7)$ & $1(7)$ & $3(7)$ & \\
\hline European & $0(0)$ & $2(13)$ & $2(4.7)$ & \\
\hline Russian & $2(7)$ & $0(0)$ & $2(4.7)$ & \\
\hline \multicolumn{5}{|l|}{ Asian verus non-Asian, $\mathrm{n}(\%)$} \\
\hline Asian & $15(54)$ & $7(47)$ & $22(51)$ & 0.666 ( $\chi^{2}$ test); 0.755 (Fisher's exact test) \\
\hline Non-Asian & $13(46)$ & $8(53)$ & $21(49)$ & \\
\hline \multicolumn{5}{|l|}{ Hepatitis, n (\%) } \\
\hline A & $2(10)$ & $0(0)$ & $2(4.7)$ & $0.742\left(\chi^{2}\right.$ test $)$ \\
\hline $\mathrm{B}$ & $8(38)$ & $2(29)$ & $10(23.3)$ & \\
\hline C & $3(14)$ & $1(14)$ & $4(9.3)$ & \\
\hline$D^{*}$ & $8(38)$ & $4(57)$ & $12(27.9)$ & \\
\hline Serum ALT ( $\times$ upper limit of normal), mean \pm SD & $6.5 \pm 6.2$ & $8.2 \pm 11.9$ & & 0.565 ( $t$ test) \\
\hline \multicolumn{5}{|l|}{ Serum HBV DNA, $\log _{10}, I \mathrm{I} / \mathrm{mL}$, mean $\pm \mathrm{SD}$} \\
\hline HBsAg loss, n (\%) & 1 (transient) (3) & 8 (1 transient) (53) & & $<0.0001$ ( $\chi^{2}$ test); 0.0003 (Fisher's exact test) \\
\hline Age, years, mean \pm SD & $10.7 \pm 5.1$ & $7.5 \pm 4.9$ & & $0.050(t$ test $)$ \\
\hline Length of treatment, mean $\pm \mathrm{SD}$ & $17.3 \pm 7.9$ & $16 \pm 5.8$ & & 0.786 ( $t$ test $)$ \\
\hline Follow-up, months, mean \pm SD & $48.6 \pm 32.1$ & $48.3 \pm 33.4$ & & 0.971 ( $t$ test $)$ \\
\hline \multicolumn{5}{|l|}{ Time necessary to respond to treatment, months } \\
\hline Mean & & 10.1 & & \\
\hline Median & & 11.0 & & \\
\hline SD & & 7.2 & & \\
\hline
\end{tabular}

${ }^{*}$ Restriction fragment length polymorphism analysis cannot distinguish between hepatitis virus (HBV) D3 and HBV E; therefore, all patients in this category have been classified as D. HBeAg Hepatitis B e antigen; HBsAg Hepatitis B surface antigen

treatment have resulted in recommendations of who to treat $(7,14$ 16). Consequently, we selected our population for the present study following recommendations outlined by Sokal et al (7), thereby focusing on patients in an immune active phase with ALT levels of at least $2 \times U L N$. Clearance of HBV infection is rarely achievable with currently available drugs, hence, our goal for therapy was based on surrogate markers previously associated with favourable long-term prognosis (4): seroconversion of $\mathrm{HBeAg}$ to $\mathrm{HBeAb}$, reduction of HBV DNA to undetectable level and normalization of ALT levels.

The present study reports a treatment success rate of $24 \%$ after 12 months of treatment, and $35 \%$ at the end of treatment (regardless of treatment duration). These results are similar to the treatment success rate of $23 \%$ after 12 months (15) and 30\% after 24 months (7) reported in previous studies. The rate of seroconversion-e achieved in our cohort in the second year of treatment reached 36\%. Undergoing a second year of treatment was, therefore, beneficial for one-third of our patients; however, LAM-resistant mutations developed only in patients who underwent a prolonged period of treatment ( $21 \%$ of patients who were treated for two years). In analyzing the results of HBV treatment protocols, spontaneous e-seroconversion is considered to occur in approximately $11 \%$ of $\mathrm{HBV}$-infected children every year (21).

Development of clinically resistant mutations (eg, YMDD mutations) with LAM treatment is the major drawback of this drug. Previous studies involving pediatric populations have reported a YMDD mutation rate of $19 \%$ to $24 \%$ after 12 months of treatment, and a mutation rate as high as $64 \%$ following a 36-month treatment 

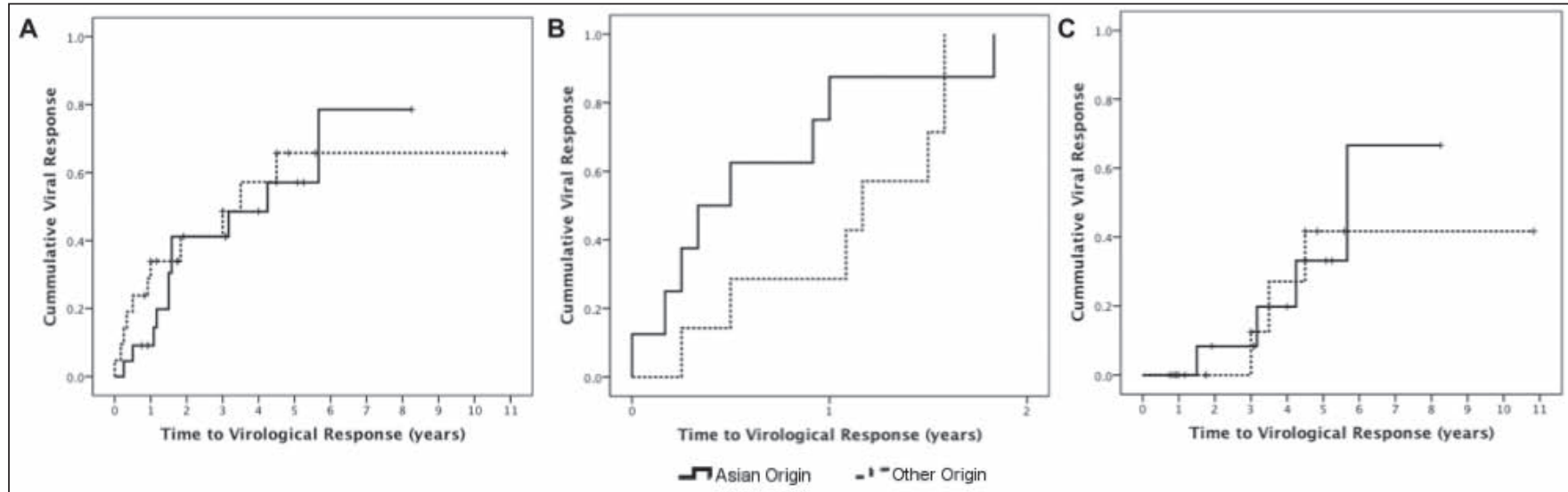

Figure 2) Asian descent does not influence time to virological response in lamivudine-treated hepatitis B virus (HBV)-infected patients. Cumulative proportion of children achieving viral control (loss of hepatitis B e antigen and loss of detectable serum HBV DNA) calculated by Kaplan-Meyer analysis. In all children $(n=43, P=0.633)(A)$, in children with successful response to treatment (B) and in children with treatment failure (C) ( $n=43, P=0.542$ [Mandel-Cox logrank test] for treatment success adjustment)
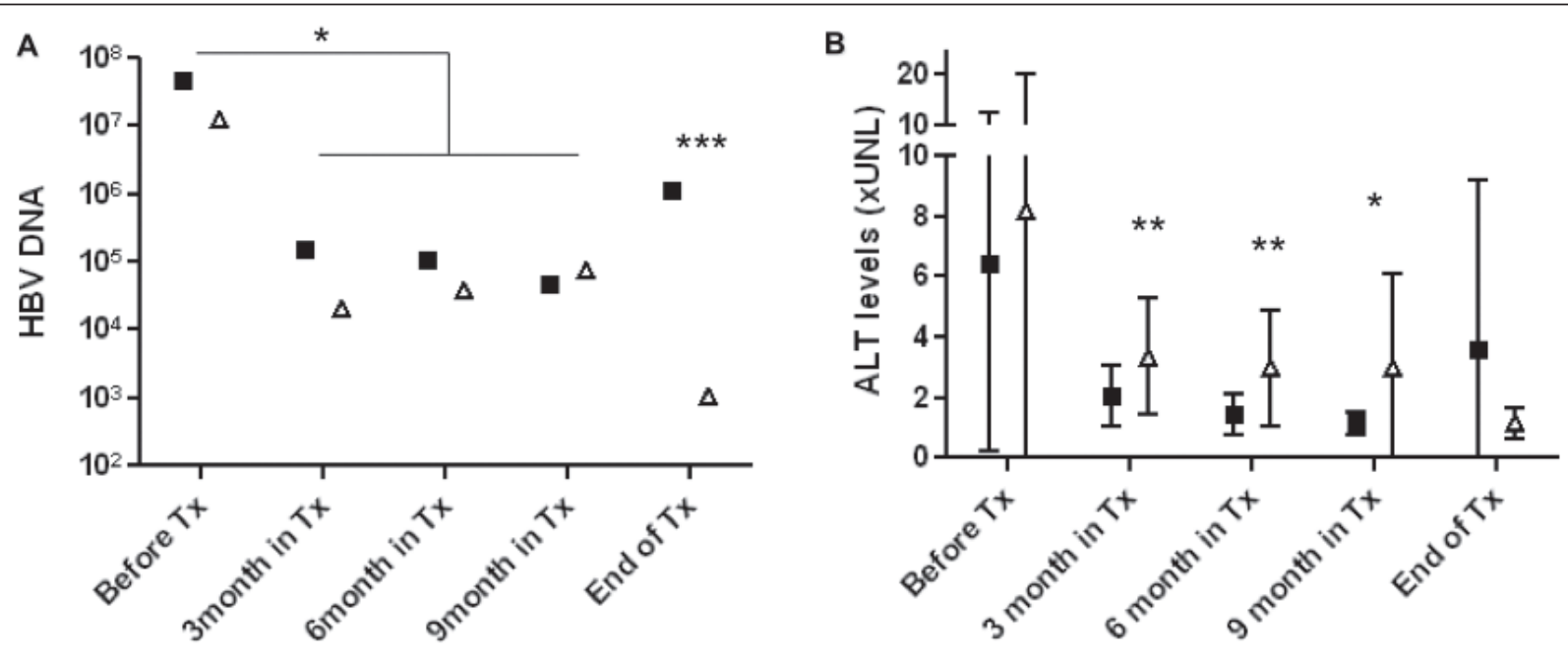

Figure 3) Hepatitis B virus (HBV) DNA and alanine aminotransferase (ALT) levels in patients with regard to treatment success. A HBV DNA levels were similar in all patients at the beginning of the treatment $(T x)(P=0.263, n=37)$, diminished during the treatment $(P=0.0245$ and $P=0.0218$ in failure and success to treatment, respectively) and was significantly lower in patients who successfully responded to treatment $(P=0.0001, n=31)$. B ALT levels were not significantly different in patients who succeeded at the beginning $(P=0.565, n=36)$ and end of treatment $(P=0.151, n=25)$; however, these patients will have significantly higher ALT levels throughout treatment $(P=0.009, n=35 ; P=0.003, n=29 ; P=0.049, n=18)$. ANOVA with Tukey post-tests; $\boldsymbol{\text { - Treatment }}$ failure; $\triangle$ Treatment success. ULN Upper limit of normal

regimen $(7,13)$. Interestingly, our patient population had a low percentage of suspected LAM-resistant mutations (11\%). Although this may be partially due to the excellent adherence of patients to treatment and the mean age of our patient population (23), other confounding factors may also be responsible for this low mutation rate. The emergence of YMDD mutation has also been associated with descent (less frequently in subjects of Asian descent), pronounced liver pathology at baseline, alcohol consumption, high viral load at inclusion $\left(>5 \times 10^{6} \mathrm{IU} / \mathrm{mL}\right)$ and previous drug treatment for HBV infections (23). Our patient population's lack of high alcohol consumption, previous drug treatment (except in two patients), pronounced viral pathology and a high proportion of patients of Asian descent could account for the low percentage of LAM-resistant mutations. As expected, patients with suspected LAM-resistant mutations in our cohort did not achieve virological response. These data are consistent with Liaw et al (24) who found no benefit in continued LAM therapy after the emergence of YMDD mutations. As for precore mutations (progression to HBeAg-negative chronic HBV), there was no significant association with treatment success and progression to this stage did not impair response to treatment. This is consistent with previous studies involving adult $(8,25)$ and pediatric $(26)$ patients.

Recently, a very high rate of recurrence in patients treated with nucleoside analogues, especially LAM, has been described in chronically HBV-infected adults (27). In our pediatric cohort, there were no issues regarding virological or serological recurrence except for one patient suspected to harbour a precore mutation. However, chronically infected children who experience $\mathrm{HBeAg}$ seroconversion have a more sustainable response and decreased chances of HBV recurrence (reappearance of detectable HBV DNA levels while maintaining seroconversion-e) compared with adult patients $(5,10,11)$. Moreover, other studies in pediatric populations have shown satisfactory sustainability in virological response subsequent to LAM treatment $(15,16)$. Furthermore, the low HBV recurrence rate in our cohort may have been due to the high rate of $\mathrm{HBs} A g$ seroconversion in patients with treatment success $(53 \%)$, which is regarded as a surrogate marker for excellent long-term outcome (4). The high degree of HBsAg loss in our study, compared with previous studies using LAM (27), may be explained by the mean age of our population (28). 
Patients of Asian descent showed no differences from other populations with respect to likelihood of treatment success or virological response when patients have been selected according to ALT levels. These results are consistent with several recent studies on treatment response $(6,14)$. In contrast, Asian descent seems to have an impact on $\mathrm{HBeAg}$ seroconversion rate in natural history of the disease. Previous studies have described more frequent/rapid spontaneous seroconversion-e and virological response in non-Asian patients $(21,29)$.

The young age of the patients was a significant predictive factor for treatment success in our cohort. A Spearman negative correlation of $-0.307(\mathrm{P}=0.045)$ was found between age groups at the beginning of treatment and treatment success. This correlation may explain approximately $10 \%$ of the variance in a population of 43 patients. Consistent with our findings, Sokal et al (7) observed a slightly higher virological response rate in patients between two and six years of age. This trend was also noted in chronically HBV-infected children treated with INF $(6,28,30)$ and led to the conclusion that beginning treatment at a younger age may prove to be beneficial in the long term. In contrast, Hom et al (14) found that age had no effect on response to LAM treatment. This discrepancy could be explained by patient inclusion criteria and the duration of treatment. Our cohort had higher ALT levels before treatment (at least two times normal values versus 1.3 times) - a known predictor of treatment success.

Other putative predictive factors of favourable outcome, such as elevated ALT levels at baseline and liver fibrosis stage $(7,13,15)$, were not statistically significant in our study. A factor that could explain this observation is the selection of our population. We selected patients with elevated ALT levels at baseline as recommended in recent reports $(7,15)$. With a mean value of $7 \times U L N$, our selected population had a favourable chance of treatment success (17), perhaps masking ALT's role as a predictive factor.

Serological and virological markers during treatment were found to be different in patients with a positive outcome to treatment. ALT levels were systematically and significantly higher in patients responding to treatment than in patients who did not respond. LAM treatment is known to result in marked elevation of ALT levels during treatment (31). This phenomenon could reflect active immunological activity in the liver leading to viral control (5).

A reduction in HBV DNA levels throughout treatment was observed in both groups of patients with no statistically significant association with treatment success. This was also observed in a pediatric study involving patients resistant to INF who were given LAM (32). However, a tendency toward lower HBV DNA levels was observed in our successfully treated patients. Similar observations were also made by Hagmann et al (13) in a small pediatric cohort. These lower values are comparable with those observed in adult patients, in which a diminution of $3.6 \log _{10}$ of HBV DNA levels at four weeks of treatment was highly predictive of treatment success at five years (8). Another study found that reaching a HBV DNA level below 10,000 copies/mL at eight weeks of treatment was predictive of a favourable outcome (33). Our study and others (13) suggest that guidelines proposed for adult patients could be applicable to chronically infected children treated with LAM.

The present study was limited by its retrospective nature and the small number of children included. Furthermore, the heterogeneity of treatment duration limits the conclusions that can be drawn with the present cohort. Interpretation of the data must be made in light of other independent studies to draw a comprehensive portrait of the LAM treatment response in chronically HBV-infected children.

There is no consensus as to whether to treat chronically HBV-infected children; treatment does not seem to augment the absolute number of patients with seroconversion-e once they reach adulthood but only accelerates the process $(21,29)$. Our conclusion is that if the decision to treat is made, LAM should be administered in well-selected patients. The recommendation to treat patients with elevated ALT levels and during the immune active phase of the disease is appropriate and our results suggest that there is a greater chance of treatment success in younger patients. Further research is needed to identify biological markers predictive of treatment outcome during the course of treatment to prevent unnecessary exposure of children to drugs. The pediatric population would benefit from studies of new therapeutics such as pegylated-IFN, new generations of nucleos(t)ide analogues and combination therapies.

ACKNOWLEDGEMENT: The authors thank Josée Beaucage for her help with chart reviews. YY is a local recipient of a scholarship award by the Millennium Foundation. PL holds a Canadian Institutes of Health Research (CIHR)/Canadian Association for the Study of the Liver (CASL) Hepatology Fellowship.

DISCLOSURES: The authors have no financial disclosures or conflicts of interest to declare.

\section{SUPPLEMENTAL TABLE 1 Baseline characteristics of children treated with lamivudine $(n=43)$}

\begin{tabular}{|c|c|}
\hline \multicolumn{2}{|l|}{ Age at beginning of treatment, years } \\
\hline Median & 9.6 \\
\hline Mean \pm SD & $9.6 \pm 5.2$ \\
\hline Range & $1.1-18.4$ \\
\hline \multicolumn{2}{|l|}{ Length of treatment, months } \\
\hline Median & 14.0 \\
\hline Mean \pm SD & $17.1 \pm 7.2$ \\
\hline Range & 5-38 \\
\hline \multicolumn{2}{|l|}{ Liver inflammation score } \\
\hline Median & 1.0 \\
\hline Mean \pm SD & $1.2 \pm 0.6$ \\
\hline Range & $0.0-3.5$ \\
\hline \multicolumn{2}{|l|}{ Liver fibrosis score } \\
\hline Median & 1.0 \\
\hline Mean \pm SD & $1.5 \pm 0.9$ \\
\hline Range & $0.0-3.5$ \\
\hline \multicolumn{2}{|l|}{ Serum ALT (x ULN) } \\
\hline Median & 3.7 \\
\hline Mean \pm SD & $7.0 \pm 8.4$ \\
\hline Range & $1.4-42.8$ \\
\hline \multicolumn{2}{|l|}{ Serum HBV, $\log _{10}, I U / m L$} \\
\hline Median & 7.6412 \\
\hline Mean \pm SD & $7.4614 \pm 1.4688$ \\
\hline Range & $0.0-9.30$ \\
\hline Sex, male:female, n:n (\%:\%) & $22: 21(51.2: 48.8)$ \\
\hline \multicolumn{2}{|l|}{ Ethnicity, n (\%) } \\
\hline Asian & $22(51.2)$ \\
\hline Not Asian & $21(48.8)$ \\
\hline African & $3(7)$ \\
\hline European & $2(4.7)$ \\
\hline Canadian & $9(20.9)$ \\
\hline Latin and South American & $3(7)$ \\
\hline Bangladeshi, Indian, Pakastani & $2(4.7)$ \\
\hline Russian & $2(4.7)$ \\
\hline \multicolumn{2}{|l|}{ Hepatitis, n (\%) } \\
\hline A & $2(4.7)$ \\
\hline B & $10(23.3)$ \\
\hline $\mathrm{C}$ & $4(9.3)$ \\
\hline$D^{*}$ & $12(27.9)$ \\
\hline Unknown & $15(34.9)$ \\
\hline \multicolumn{2}{|l|}{ Transmission, n (\%) } \\
\hline Horizontal & $6(14)$ \\
\hline Vertical (or perinatally) & $37(86)$ \\
\hline
\end{tabular}

${ }^{*}$ Restriction fragment length polymorphism analysis cannot distinguish between hepatitis virus (HBV) D3 and HBV E; therefore, all patients in this category have been classified as $D$ 


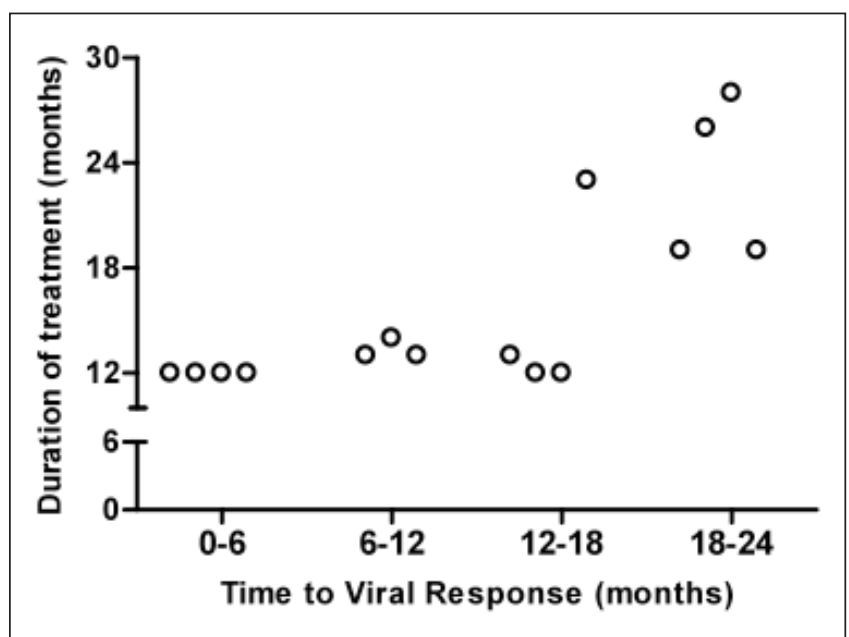

Supplemental Figure 1) Time to viral response in hepatitis $B$ virus (HBV)-infected patients with successful response to lamivudine according to duration of treatment. Five of 15 patients (33\%) who successfully responded to treatment achieved a viral control in their second year of treatment (loss of hepatitis B e antigen and loss of detectable serum HBV DNA)

\section{REFERENCES}

1. Sorrell MF, Belongia EA, Costa J, et al. National Institutes of Health consensus development conference statement: Management of hepatitis B. Hepatology 2009;49:S4-S12.

2. Marotta P, Lucas K. Management of hepatitis B: A longitudinal national survey - impact of the Canadian Hepatitis B Consensus Guidelines. Can J Gastroenterol 2010;24:537-42.

3. Hoofnagle JH, di Bisceglie AM. The treatment of chronic viral hepatitis. N Engl J Med 1997;336:347-56.

4. Feld JJ, Wong DK, Heathcote EJ. Endpoints of therapy in chronic hepatitis B. Hepatology 2009;49:S96-S102.

5. Chang $\mathrm{MH}$. Natural history and clinical management of chronic hepatitis B virus infection in children. Hepatol Int 2008;2:28-36.

6. Sokal EM, Conjeevaram HS, Roberts EA, et al. Interferon alfa therapy for chronic hepatitis B in children: A multinational randomized controlled trial. Gastroenterology 1998;114:988-95.

7. Sokal EM, Kelly DA, Mizerski J, et al. Long-term lamivudine therapy for children with $\mathrm{HBeAg}$-positive chronic hepatitis B. Hepatology 2006;43:225-32.

8. Yuen MF, Fong DY, Wong DK, et al. Hepatitis B virus DNA levels at week 4 of lamivudine treatment predict the 5 -year ideal response. Hepatology 2007;46:1695-703.

9. Chang TT, Lai CL, Chien RN, et al. Four years of lamivudine treatment in Chinese patients with chronic hepatitis B. J Gastroenterol Hepatol 2004;19:1276-82.

10. Bortolotti F, Guido M, Bartolacci S, et al. Chronic hepatitis B in children after e antigen seroclearance: Final report of a 29-year longitudinal study. Hepatology 2006;43:556-562.

11. Bortolotti F, Cadrobbi P, Crivellaro C, et al. Long-term outcome of chronic type $\mathrm{B}$ hepatitis in patients who acquire hepatitis $\mathrm{B}$ virus infection in childhood. Gastroenterology 1990;99:805-10.

12. Iorio R, Giannattasio A, Cirillo F, D'Alessandro L, Vegnente A. Long-term outcome in children with chronic hepatitis B: A 24-year observation period. Clin Infect Dis 2007;45:943-9.

13. Hagmann S, Chung M, Rochford G, et al. Response to lamivudine treatment in children with chronic hepatitis B virus infection. Clin Infect Dis 2003;37:1434-40.
14. Hom X, Little NR, Gardner SD, Jonas MM. Predictors of virologic response to lamivudine treatment in children with chronic hepatitis B infection. Pediatr Infect Dis J 2004:23:441-5.

15. Jonas MM, Mizerski J, Badia IB, et al. Clinical trial of lamivudine in children with chronic hepatitis B. N Engl J Med 2002;346:1706-13.

16. Jonas MM, Little NR, Gardner SD. Long-term lamivudine treatment of children with chronic hepatitis B: Durability of therapeutic responses and safety. J Viral Hepat 2008;15:20-27.

17. Ni YH, Huang FC, Wu TC, et al. Lamivudine treatment in maternally transmitted chronic hepatitis B virus infection patients. Pediatr Int 2005;47:372-7.

18. Bedossa P, Poynard T. An algorithm for the grading of activity in chronic hepatitis C. The METAVIR Cooperative Study Group. Hepatology 1996;24:289-93.

19. Costa J, Lopez-Labrador FX, Sanchez-Tapias JM, et al. Microwave treatment of serum facilitates detection of hepatitis B virus DNA by the polymerase chain reaction. Results of a study in anti-HBe positive chronic hepatitis B. J Hepatol 1995;22:35-42.

20. Lindh M, Andersson AS, Gusdal A. Genotypes, nt 1858 variants, and geographic origin of hepatitis B virus - large-scale analysis using a new genotyping method. J Infect Dis 1997;175:1285-93.

21. Marx G, Martin SR, Chicoine JF, Alvarez F. Long-term follow-up of chronic hepatitis $B$ virus infection in children of different ethnic origins. J Infect Dis 2002;186:295-301.

22. Evans AA, Fine M, London WT. Spontaneous seroconversion in hepatitis B e antigen-positive chronic hepatitis B: Implications for interferon therapy. J Infect Dis 1997;176:845-50.

23. Zoulim F, Poynard T, Degos F, et al. A prospective study of the evolution of lamivudine resistance mutations in patients with chronic hepatitis B treated with lamivudine. J Viral Hepat 2006;13:278-88.

24. Liaw YF, Chien RN, Yeh CT. No benefit to continue lamivudine therapy after emergence of YMDD mutations. Antivir Ther 2004;9:257-62.

25. Shin JW, Chung YH, Choi MH, et al. Precore stop codon mutation of hepatitis $B$ virus is associated with low breakthrough rate following long-term lamivudine therapy. J Gastroenterol Hepatol 2005;20:844-9.

26. Cho SW, Hahm KB, Kim JH. Reversion from precore/core promoter mutants to wild-type hepatitis $\mathrm{B}$ virus during the course of lamivudine therapy. Hepatology 2000;32:1163-9.

27. Reijnders JG, Perquin MJ, Zhang N, Hansen BE, Janssen HL. Nucleos $(\mathrm{t})$ ide analogues only induce temporary hepatitis B e antigen seroconversion in most patients with chronic hepatitis B. Gastroenterology;139:491-8.

28. Kobak GE, MacKenzie T, Sokol RJ, Narkewicz MR. Interferon treatment for chronic hepatitis B: Enhanced response in children 5 years old or younger. J Pediatr 2004;145:340-5.

29. Yeung LT, Ling SPC, Ng VL, O'Conor C, Roberts EA. Achieving inactive carrier status in childhood hepatitis $\mathrm{B}$ virus infection: 25 years' experience. Hepatology 2010;54:1027A.

30. Choe BH, Lee JH, Jang YC, et al. Long-term therapeutic efficacy of lamivudine compared with interferon-alpha in children with chronic hepatitis B: The younger the better. J Pediatr Gastroenterol Nutr 2007;44:92-8.

31. Dienstag JL. Benefits and risks of nucleoside analog therapy for hepatitis B. Hepatology 2009;49:S112-21.

32. Hartman C, Berkowitz D, Shouval D, et al. Lamivudine treatment for chronic hepatitis $B$ infection in children unresponsive to interferon. Pediatr Infect Dis J 2003;22:224-9.

33. Chan HL, Wong VW, Wong GL, et al. Early hepatitis B virus DNA suppression can predict virologic response to peginterferon and lamivudine treatment. Clin Gastroenterol Hepatol 2008;6:1022-6. 


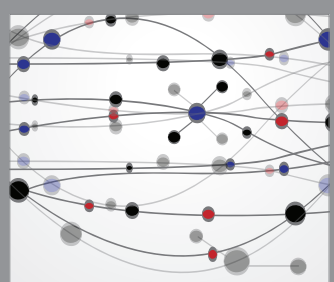

The Scientific World Journal
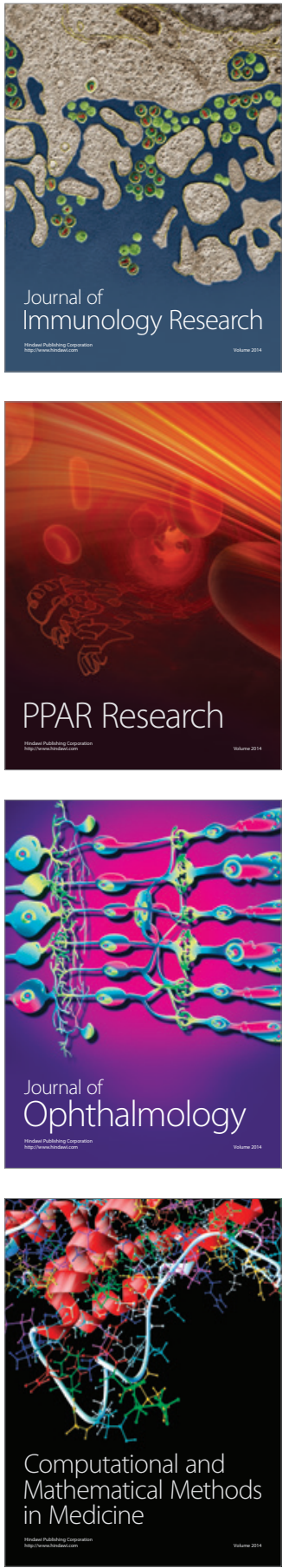

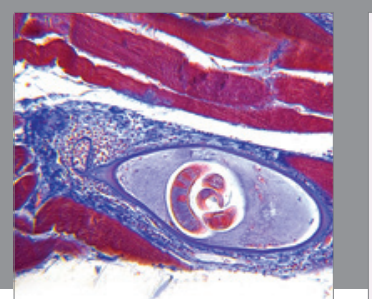

Gastroenterology Research and Practice

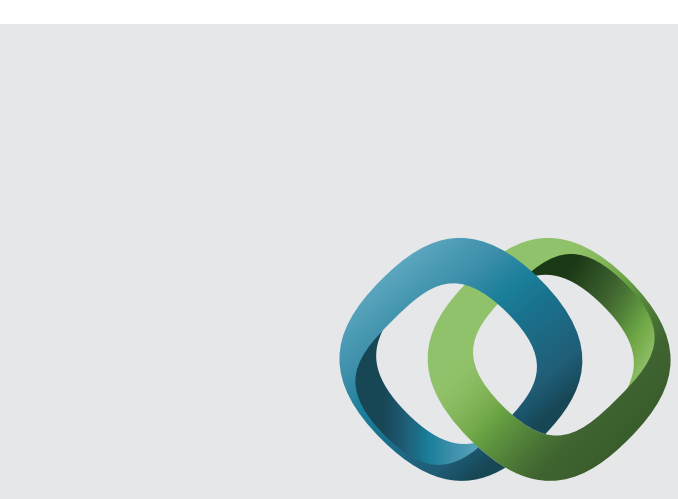

\section{Hindawi}

Submit your manuscripts at

http://www.hindawi.com
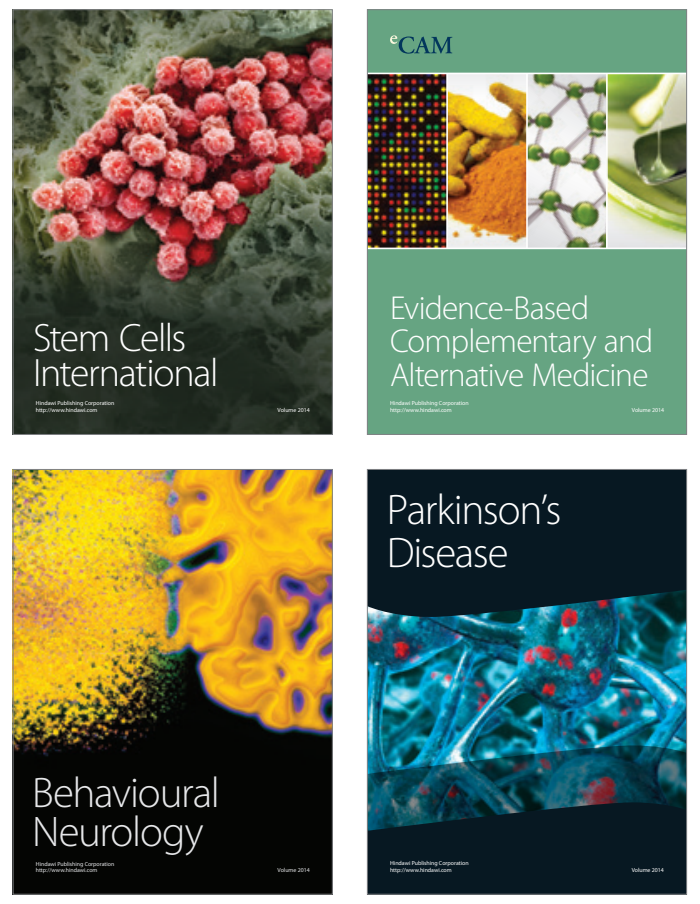
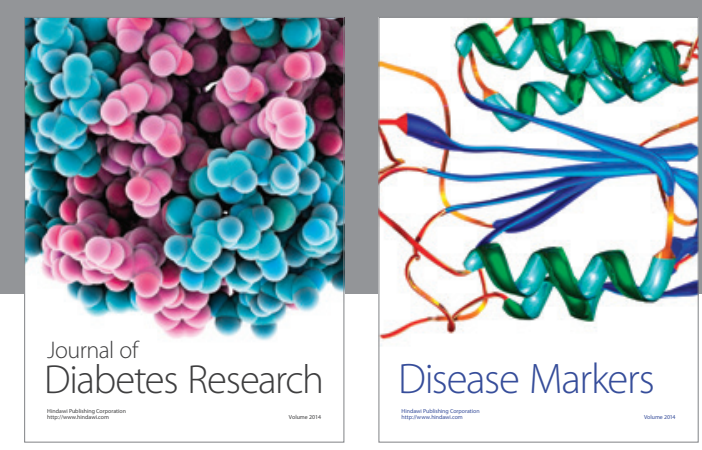

Disease Markers
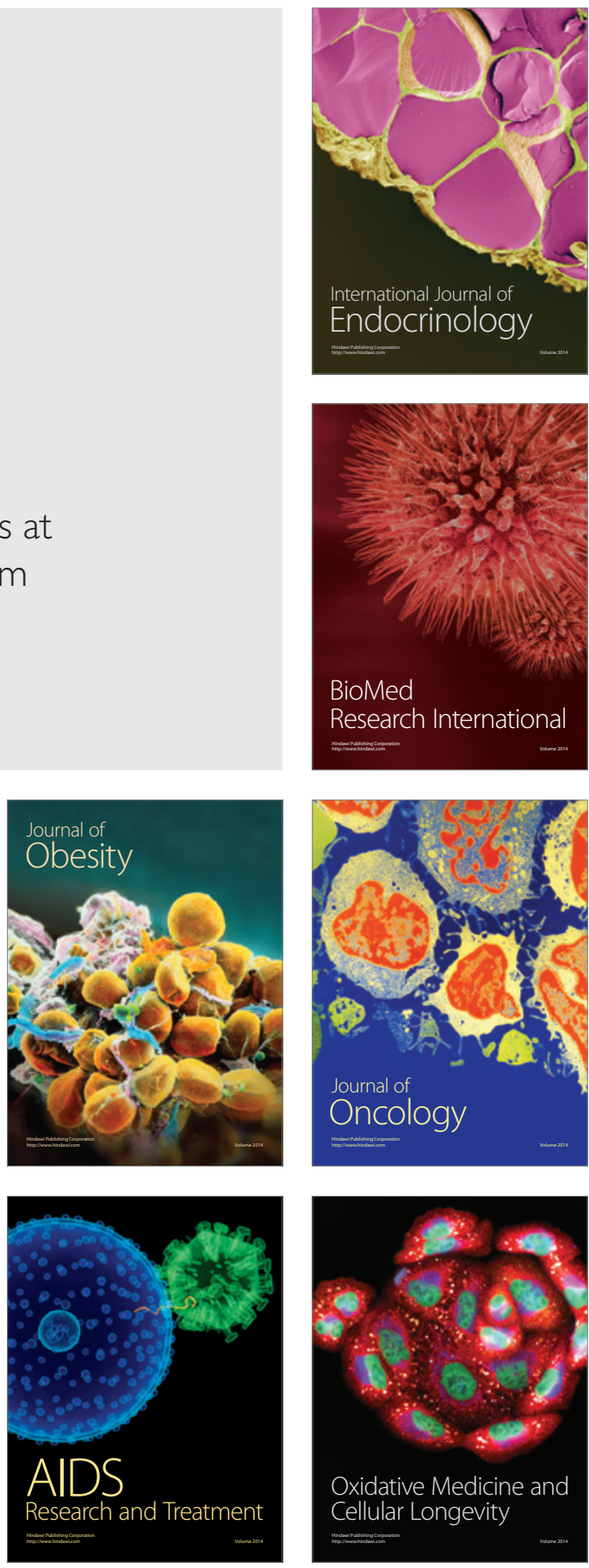